\section{POROSITY IN POLYSILSESQUIOXANE XEROGELS}

Douglas A. Loy*, Duane A. Schneider, and Brigitta M. Baugher

Catalysts and Chemical Technologies Department, Sandia National Laboratories, Albuquerque, NM 87185-1407

Kamyar Rahimian

Organic Materials Department, Sandia National Laboratories, Albuquerque, NM 87185-1407

\section{Introduction}

Polysilsesquioxanes, $\left[\mathrm{RSiO}_{1.5}\right]_{\mathrm{n}}$, are a class of hybrid organicinorganic materials in which silicon atoms are linked with up to three siloxane bonds to other monomer units in the polymer and the organic group is a pendent functionality. Polysilsesquioxanes are prepared by the hydrolysis and condensation of organotrialkoxysilanes (Scheme 1). Organotrialkoxysilanes $\operatorname{RSi}\left(\mathrm{OR}^{\prime}\right)_{3}$, have been extensively used as coupling agents for composites or surface treatments for materials. ${ }^{2}$ Polysilsesquioxanes have become increasingly popular for generating specialty coatings such as low $\mathrm{k}$ dielectric materials for microelectronic applications. ${ }^{3}$ While there is extensive information on the formation of polysilsesquioxanes, ${ }^{1}$ there has not been a survey of the ability of organotrialkoxysilanes to form gels until recently., ${ }^{4,5}$ The formation of polysilsesquioxanes gels has been shown to be very sensitive to the nature of the organic group. Many monomers will only form soluble oligomers or polymers upon hydrolysis and condensation, even when the reaction is conducted solvent-free with neat monomer and aqueous catalyst. Furthermore, there is little information concerning the influence of the organic group, $R$, on the porosity of the polysilsesquioxanes gels that are formed. ${ }^{6}$ In this paper we describe the preparation of polysilsesquioxane gels where $R=H$, methyl, ethyl, cyanoethyl, vinyl, dodecyl, hexadecyl, octadecyl, chloromethyl, and chloromethylphenyl, and the characterization of the porosity of the respective xerogels. Gels were prepared from the hydrolysis and condensation of organotrimethoxysilanes, RSi(OMe) ${ }_{3}$, and organotriethoxy-silanes, $\mathrm{RSi}(\mathrm{OEt})_{3}$.

$$
\begin{aligned}
& n \mathrm{R}^{-\mathrm{Si}\left(\mathrm{OR}^{\prime}\right)_{3}} \underset{\text { cat. } \mathrm{H}+\text { or } \mathrm{OH}-}{\frac{1.5 \mathrm{n} \mathrm{H}_{2} \mathrm{O}}{\longrightarrow}}\left[\mathrm{R}-\mathrm{SiO}_{1.5}\right]_{n} \\
& -3 n \mathrm{EtOH}
\end{aligned}
$$

Scheme 1. Sol-gel formation of polysilsesquioxanes.

\section{Experimental}

Anhydrous methanol was purchased from Aldrich. Ethanol was distilled from magnesium before use. ' $\mathrm{H}$ nuclear magnetic resonance (NMR) spectra were recorded on a Bruker $\mathrm{AM} 400(400 \mathrm{MHz})$ using $\mathrm{C}_{6} \mathrm{D}_{6}$ or $\mathrm{CDCl}_{3}$ as solvent. Triethoxysilane, trimethoxysilane, methyltrimethoxysilane, methyltriethoxysilane, vinyltrimethoxysilane, ethyltriethoxysilane, cyanoethyltriethoxysilane, vinyltriethoxysilane, chloromethyltrimethoxyne, chlorotriethoxysilane, chloromethylphenyltrimethoxysilane hexadecyltrimethoxysilane, hexadecyltriethoxysilane and $n$-octadecyltrimethoxysilane were purchased from Aldrich. Monomer purities were checked by $\mathrm{GC},{ }^{13} \mathrm{C}$ and ${ }^{29} \mathrm{Si} \mathrm{NMR}$ and the monomers were distilled, if necessary, until purities greater than $96 \%(\mathrm{GC})$ were achieved. Monomers were generally polymerized with 1.5 equivalents of water in triplicate at $1 \mathrm{M}$ concentration in the appropriate alcohol (methanol for trimethoxysilanes; ethanol for triethoxysilanes). Aqueous $\mathrm{HCl}(\mathrm{IN})$ and $\mathrm{NaOH}(1 \mathrm{~N})$ were used as catalysts $(2.7 \mathrm{~mol} \%$ catalyst relative to monomer concentration). If gels were obtained, the monomer was then polymerized at lower concentrations to determine where the practical gelation threshold lies. If the monomer did not gel in within 7-14 days, it was polymerized at as high a concentration as possible (based on the molecular weight and density of the monomer). Gels were described as either colloidal (opaque white), translucent (blue tinted) or transparent.

\section{Results and Discussion}

Table 1 lists the monomers that formed gels, the conditions under which they formed, and a brief description of the gel before drying. The main difference between the polymerization of organotrimethoxysilanes and organotriethoxysilanes was the greater reactivity of the former to hydrolysis and condensation reactions. While this often did not translate to faster gelation times, it did result in more of the organotrimethoxysilanes forming gels under not only acid and base conditions, but with just de-ionized water (pH 7) as well. Another consequence of these polymerizations, particularly with neat monomer, was the rapid exotherm during mixing associated with the acid-catalyzed hydrolysis of the organotrimethoxysilane. For example, the polymerization reaction of neat methyltrimethoxysilane with aqueous acid rapidly came to a boil and sprayed from the reaction vessel.

Table 1. Organotrialkoxysilanes that formed gels at concentrations ranging from $0.1 \mathrm{M}$ to neat monomer. Polymerizations with 1.5 equivalents water and 2.7 mol\% catalyst in methanol (for RSi(OMe) $)_{3}$ ) or ethanol (for $\mathrm{RSi}(\mathrm{OEt})_{3}$ ).

\begin{tabular}{|c|c|c|c|c|c|c|}
\hline \multirow[b]{2}{*}{$\mathbf{R}$} & \multicolumn{3}{|c|}{$\mathrm{RSi}(\mathrm{OMe})_{3}$} & \multicolumn{3}{|c|}{ RSi(OEt) $)_{3}$} \\
\hline & $\mathrm{H}^{+}$ & $\mathrm{OH}^{-}$ & $\mathrm{H}_{2} \mathrm{O}$ & $\mathrm{H}^{+}$ & $\mathrm{OH}^{-}$ & $\mathrm{H}_{2} \mathrm{O}$ \\
\hline $\mathrm{H}$ & transl. & transl. & transl. & transp. & transp. & $\ldots$ \\
\hline $\mathrm{CH}_{3}$ & opaque & transl. & $\ldots$ & transl. & opaque & -- \\
\hline $\mathrm{CH}_{3} \mathrm{CH}_{2}$ & $\cdots$ & $\cdots$ & --- & --- & opaque & --- \\
\hline Dodecyl & --- & $\cdots$ & --- & opaque & opaque & $-\cdots$ \\
\hline Hexadecyl & opaque & opaque & opaqué & opaque & opaque & -- \\
\hline Octadecyl & opaque & opaque & opaque & $\ldots$ & -- & $\ldots$ \\
\hline Vinyl & opaque & opaque &.- & transl. & opaque & $\cdots$ \\
\hline $\mathrm{ClCH}_{2}$ & transl. & opaque & transp. & $-\cdots$ & opaque & transp. \\
\hline (p-ClCH$)_{2}$ )phenyl & -- & opaque & opaque & $\cdots$ & -- & -- \\
\hline $\mathrm{CNCH}_{2} \mathrm{CH}_{2}$ & $-\cdots$ & $\cdots$ & - & -- & opaque & -- \\
\hline
\end{tabular}
Gels are described as transparent (transp.), translucent (transl.) or opaque.

Many of the polysilsesquioxane gels were opaque white and colloidal in appearance before drying. Transparent or translucent gels were only obtained from the trialkoxysilanes, methyltrialkoxysilanes, vinyltrimethoxysilane, and chloromethyltrialkoxysilanes. Once formed, the gels with $\mathrm{R}=\mathrm{H}$, methyl, ethyl, cyanoethyl, vinyl, chloromethyl, and chloromethylphenyl were not thermo-reversible; with the exception of the chloromethylphenylsilsesquioxane gel (apparently an oligomer) prepared with water from neat methoxy monomer, the xerogels did not revert to solutions with heat. Under the same conditions, tetramethoxysilane and tetraethoxysilane form transparent or translucent silica gels. Upon aqueous work-up, the gels were all opaque white materials. These xerogels were insoluble, non-swelling materials.

While both trimethoxy- and triethoxysilane $(R=H)$ reacted exothermically under basic conditions to quantitatively give silica, ${ }^{7}$ xerogels prepared under neutral conditions were found (by solid state ${ }^{29} \mathrm{Si}$ NMR) to be a mixture of silica and $\left[\mathrm{HSiO}_{1.5}\right]_{\mathrm{n}}$ The organic groups on the remaining monomers proved to be stable under sol-gel conditions. The only organic groups that could potentially be chemically modified are the chloromethyl and p-chloromethylphenyl groups. These groups might be expected to undergo nucleophilic substitution reactions with hydroxide ions present under basic conditions. However, under the sol-gel conditions used in these experiments the chloride substitutents in the chloromethyltrialkoxysilanes ${ }^{8}$ and chloromethylphenyl-trimethoxysilane did not react, even when basic catalysts were used. Both ${ }^{29}$ Si NMR and chlorine elemental analysis showed that little, if any, of the chlorine was lost during the sol-gel process.

Unlike other xerogels, polysilsesquioxane xerogels prepared from the dodecyl, hexadecyl, and octadecyl-substituted monomers melted between $45^{\circ} \mathrm{C}$ and 75 ${ }^{\circ} \mathrm{C}$ (This prevented porosimetry data from being obtained because the samples need to be dried before the isotherm is measured, typically at $100^{\circ} \mathrm{C}$ under vacuum.). Gels of poly(octadecylsilsesquioxane) were recently reported by 
Shimojima et. al.. ${ }^{9}$ Gelation was attributed to self-organization of the long chain aliphatic organic groups. Scanning and transmission electron micrographs of these materials were consistent with non-porous materials, but revealed no ordered supramolecular architectures. Interestingly, we found that the gels (before drying) of these monomers were thermoreversible. Solutions of the materials in hot benzene $\left(80^{\circ} \mathrm{C}\right)$ were cooled and converted into transparent monolithic gels. Characterization of these materials is in progress.

Table 2. Surface areas and mean pore diameters for different $R$ groups in $\mathrm{RSi}(\mathrm{OMe})_{3}$ based polysilsesquioxane xerogels. (a) Gels were obtained at 1.0 $\mathrm{M}$ monomer concentration. (b) Monomer reacts violently, boiling the solution. (c) Gels were obtained at neat monomer concentration.

\begin{tabular}{|c|c|c|c|c|c|c|}
\hline \multirow{2}{*}{ Catalyst } & \multicolumn{5}{|c|}{ Surface Area $\left(\mathrm{m}^{2} / \mathrm{g}\right) /($ Pore Diameter $(\AA))$} \\
\cline { 2 - 7 } & $\mathrm{OMe}$ & $\mathrm{H}$ & $\mathrm{Me}$ & Vinyl & $\mathrm{ClCH}_{2}$ & $\mathrm{ClCH}_{2} \mathrm{Ph}$ \\
\hline $\mathrm{H}+$ & $246(22)^{\mathrm{a}}$ & $617(67)^{\mathrm{a}}$ & $\begin{array}{c}\text { Non- } \\
\text { porous }\end{array}$ & $\begin{array}{c}\text { Non- } \\
\text { porous }\end{array}$ & $\begin{array}{c}\text { Non- } \\
\text { porous }\end{array}$ & $\begin{array}{c}\text { Non- } \\
\text { porous }\end{array}$ \\
\hline $\mathrm{H}_{2} \mathrm{O}$ & $342(50)^{\mathrm{a}}$ & $393(45)^{\mathrm{a}}$ & No Gels & No Gels & $28(380)^{\mathrm{a}}$ & $\begin{array}{c}\text { Non- } \\
\text { porous }\end{array}$ \\
\hline $\mathrm{OH}-$ & $212(65)^{\mathrm{a}}$ & Reacts $^{\mathrm{b}}$ & $566(45)^{\mathrm{a}}$ & $70(407)^{\mathrm{a}}$ & $20(750)^{\mathrm{a}}$ & $\begin{array}{c}\text { Non- } \\
\text { porous }\end{array}$ \\
\hline
\end{tabular}

Table 3. Surface areas and mean pore diameters for different $R$ groups in $\mathrm{RSi}(\mathrm{OEt})_{3}$ based polysilsesquioxane xerogels. (a) Gels were obtained at $1.0 \mathrm{M}$ monomer concentration. (b) Monomer reacts violently, boiling the solution. (c) Gels were obtained at neat monomer concentration.

\begin{tabular}{|c|c|c|c|c|c|c|}
\hline \multirow{2}{*}{ Catalyst } & \multicolumn{5}{|c|}{ Surface Area $\left(\mathrm{m}^{2} / \mathrm{g}\right) /$ Pore Diameter $(A)$} \\
\cline { 2 - 7 } & $\mathrm{OEt}$ & $\mathrm{H}$ & $\mathrm{Me}$ & Vinyl & $\mathrm{ClCH}_{2}$ & NCEt \\
\hline $\mathrm{H}+$ & No Gels & $766(40)^{\mathrm{a}}$ & $226(56)^{\mathrm{c}}$ & $\begin{array}{c}\text { Non- } \\
\text { porous }\end{array}$ & $\begin{array}{c}\text { Non- } \\
\text { porous }\end{array}$ & No Gels \\
\hline $\mathrm{H}_{2} \mathrm{O}$ & $637(84)^{\mathrm{a}}$ & $662(41)^{\mathrm{a}}$ & No Gels & No Gels & $51(240)^{\mathrm{a}}$ & No Gels \\
\hline $\mathrm{OH}-$ & No Gels & Reacts & $\begin{array}{c}281 \\
(214)^{\mathrm{a}}\end{array}$ & $\begin{array}{c}140 \\
(338)^{\mathrm{a}}\end{array}$ & $63(478)^{\mathrm{a}}$ & $\begin{array}{c}\text { Non- } \\
\text { porous }\end{array}$ \\
\hline
\end{tabular}

Surface area and mean pore size data for the polysilsesquioxanes are displayed in Table 2 for xerogels prepared from organotrimethoxysilanes and in Table 3 for xerogels prepared from organotriethoxysilanes. Xerogels with $\mathrm{R}=\mathrm{H}$ or $\mathrm{Me}$ exhibited the highest surface areas $\left(>500 \mathrm{~m}^{2} / \mathrm{g}\right)$ and pores in the lower mesopore range $(<100 \AA)$. Most of the polysilsesquioxanes with organic groups had lower surface areas and larger pores than the polysilsesquioxanes with $\mathrm{R}=\mathrm{H}$, or were non-porous completely. Xerogels prepared under acidic conditions were often non-porous, whereas those prepared under basic conditions were generally porous. Exceptions to this were the chloromethylphenyl substituted polysilsesquioxane xerogels which were nonporous regardless of the experimental conditions used in their preparation. Xerogels prepared from sol-gel polymerizations run at higher monomer concentration generally possessed lower surface areas or were non-porous.

Scanning electron microscopy supplements porosimetry data by providing information regarding macropores [(mean pore diameter $>500 \AA$ ) that can not be evaluated using nitrogen soprtion techniques.]. For instance, the polysilsesquioxane xerogel prepared from $\mathrm{HSi}(\mathrm{OMe})_{3}$ under acidic conditions was determined to have a surface area of $667 \mathrm{~m}^{2} / \mathrm{g}$ and a mean pore diameter of $67 \AA$ by nitrogen sorption. The SEM of the material revealed no macroporosity. In contrast, the polysilsesquioxane xerogels prepared from methyltriethoxysilane exhibits significant macroporosity in addition to the mesopores observed by nitrogen sorption. The xerogel prepared from chloromethylphenyltrimethoxysilane is non-porous by nitrogen sorption and has no visible macroporosity by SEM. Because the hexadecyltriethoxysilsesquioxane xerogel melts between $45^{\circ} \mathrm{C}$ and $75^{\circ} \mathrm{C}$, it has not been possible to obtain porosity measurements. However, the SEM reveals no macroporosity.

\section{Conclusions}

Polysilsesquioxane xerogels were prepared by the sol-gel polymerization of organotrialkoxysilanes, $\mathrm{RSi}\left(\mathrm{OR}^{\prime}\right)_{3}$, with $\mathrm{R}^{\prime}=\mathrm{Me}: \mathrm{R}=\mathrm{H}, \mathrm{Me}$, vinyl, chloromethyl, chloromethylphenyl, hexadecyl, and octadecyl and $\mathrm{R}^{\prime}=\mathrm{Et}: \mathrm{R}=$ $\mathrm{H}, \mathrm{Me}, \mathrm{Et}$, cyanoethyl, chloromethyl, vinyl, dodecyl, and hexadecyl. The majority of the gels were opaque and colloidal in appearance. The gels with $R$ $=\mathrm{H}, \mathrm{Me}$, and chloromethyl were the most transparent. The porosity of the xerogels was characterized by nitrogen porosimetry and scanning electron microscopy. Xerogels prepared from trimethoxysilane and triethoxysilane had the highest surface areas. Many of the remaining organotrialkoxysilanes formed porous polymeric gels, but the surface areas were lower and the mean pore sizes larger. Some of the xerogels, especially those prepared under acidic conditions, were non-porous.

Acknowledgement. Sandia is a multiprogram laboratory operated by Sandia Corporation, a Lockheed Martin Company, for the United States Department of Energy under Contract DE-AC04-94AL85000

\section{References}

(1) Baney, R. H.; Itoh, M.; Sakakibara, A.; Suzuki, T. Chem. Rev., 1995, 95, 1409.

(2) E. P. Plueddemann, Silane Coupling Agents (Plenum: New York, 1982).

(3) Kim, S. M.; Yoon, D. Y.; Nguyen, C. V.; Han, J; Jaffe, R. L. in LowDielectric Constant Materials III (Mater. Res. Soc. Symp. Proc. 511, Pittsburg, PA, 1998), 39-47.

(4) Loy, D. A.; Baugher, B. M.; Schneider, D. A. Polym. Prepr. (Am. Chem. Soc., Div. Polym. Chem.), 1998, 39(2), 418-419.

(5) Schneider, D. A.; Loy, D. A.; Baugher, B. M.; Wheeler, D. R.; Assink, R. A.; Alam, T. M.; Saunders, R. Polym. Prepr. (Am. Chem. Soc., Div. Polym. Chem.), 1998, 39(2), 513-514.

(6) Slinyakova, I. B.; Kurennaya, L. I. Vysokomol. Soedin., Ser. B. 1972, 14, 889.

(7) Kaneko, K. J. Membr. Sci., 1994, 96(1+2), 59-89.

(8) Pauthe, M.; Phalippou, J.; Corriu, R. J. P.; Leclercq, D.; Vioux, A. $J$. Non-Cryst. Solid 1989, 113, 21.

(9) Shimojima, A.; Sugahara, Y; Kuroda, K. Bull. Chem. Soc. Jpn. 1997, 70,2847 . 


\section{DISCLAIMER}

This report was prepared as an account of work sponsored by an agency of the United States Government. Neither the United States Government nor any agency thereof, nor any of their employees, make any warranty, express or implied, or assumes any legal liability or responsibility for the accuracy, completeness, or usefulness of any information, apparatus, product, or process disclosed, or represents that its use would not infringe privately owned rights. Reference herein to any specific commercial product, process, or service by trade name, trademark, manufacturer, or otherwise does not necessarily constitute or imply its endorsement, recommendation, or favoring by the United States Government or any agency thereof. The views and opinions of authors expressed herein do not necessarily state or reflect those of the United States Government or any agency thereof. 


\section{DISCLAIMER}

Portions of this document may be illegible in electronic image products. Images are produced from the best available original document. 